\title{
Differential scanning calorimetric studies on frozen cephalosporin solutions
}

\author{
N. Adeyinka Williams ${ }^{1, *}$ and G.P. Polli ${ }^{2}$ \\ ${ }^{1}$ College of Pharmacy, University of Michigan, Ann Arbor, MI 48109-1065 (U.S.A.) and ${ }^{2}$ Smith Kline \& French Laboratories, Research \\ and Development Division, King of Prussia, PA 19406-0939 (U.S.A)
}

(Received 21 July 1987)

(Modified version received 30 November 1987)

(Accepted 16 December 1987)

Key words: Differential scanning calorimetry; Cephalosporin; Eutectic; Degree of supercooling; Freeze-drying; Glass transition; Metastable state; Temperature of complete solidification;

Temperature of incipient melting

\section{Summary}

The difficulty of formulating cephalosporins as freeze-dried products lies in the freezing characteristics of their aqueous solutions. The thermal characteristics of aqueous solutions of several cephalosporins were examined by Differential Scanning Calorimetry (DSC) during freezing and warming cycles. It was found that the observed compounds do not crystallize from such solutions and do not form eutectic mixtures with water. Also, freezing did not produce any detectable metastable states of the solutes. Therefore, in the determination of parameters to be used in designing an optimum freeze-drying cycle for compounds such as these, DSC may be of limited use.

\section{Introduction}

Freeze-drying (lyophilization) (Flosdorf, 1949; Harris, 1954) is now a fairly common process that has found considerable use in the pharmaceutical industry in the preparation of parenteral dosage forms (DeLuca, 1977; Williams and Polli, 1984). The process consists of freezing a solution of the

\footnotetext{
* This work was conducted by N.A. Williams, as a Post-Doctoral Scientist in the Pharmaceutics Department of Smith Kline \& French Laboratories.

Correspondence: G.P. Polli, Smith Kline \& French Laboratories, Research and Development Division, P.O. Box 1539, King of Prussia, PA 19406-0939, U.S.A..
}

drug substance and other excipients in vials on a freeze-dryer shelf, reducing the pressure in the freeze-dryer chamber and raising the temperature of the frozen solution, thereby subliming the ice. Any water absorbed by, or absorbed onto, the solid particles is subsequently evaporated by further temperature increase of the product in the vial. During the sublimation of the ice, the product temperature must not reach the eutectic temperature of the product because the product would be ruined by what is termed "melt-back". Properly done, freeze-drying does not cause significant decomposition of heat-sensitive compounds (antibiotic, peptides and proteins), and yields a dry, stable end-product which can be reconstituted with ease. 
In preparation of lyophilized drug delivery systems, it is becoming increasingly clear that studies need to be done on the freezing characteristics of such solutions before they are freeze-dried (Gatlin and Deluca, 1980; Jennings 1980a). One method of characterizing solutions that is in use is Differential Scanning Calorimetry (Patel and Hurwitz, 1972; Jennings, 1980a). Others are Differential Thermal Analysis (DTA) (Rey, 1960) and electrical resistance measurements (Rey, 1960; DeLuca and Lachman, 1965a and b). In order to design an optimal lyophilization process, data on temperature of complete solidification, temperature of incipient melting, occurrence of metastable states and the degree of supercooling must be obtained for each system. Each of these properties is briefly described in the following paragraphs.

(1) The temperature of complete solidification $\left(T_{\mathrm{cs}}\right)$, is the temperature below which no liquid phase is present in the solution (Rey, 1964). Failure to achieve complete solidification of a solution before freeze-drying may cause the incompletely formed solid matrix to collapse during the drying phase, resulting in an unacceptable product. To avoid matrix collapse, the solution must first be frozen to a temperature at least $10^{\circ} \mathrm{C}$ below $T_{\mathrm{cs}}$ in order to ensure complete solidification (Rey, 1964).

(2) The temperature of incipient melting $\left(T_{\mathrm{im}}\right)$ is the temperature at which a liquid phase begins to appear in the frozen solution during warming. For solutes which form eutectic mixtures with water, $T_{\mathrm{im}}$ is identical to the eutectic temperature $\left(T_{\text {eu }}\right)$. During freeze-drying, the temperature of the product should not reach $T_{\text {im }}$ or a melt-back will occur with consequent ruin of the product. $T_{\mathrm{cs}}$ is typically a few degrees lower than $T_{\mathrm{im}}$ because liquid phases tend to undergo some supercooling before freezing.

(3) During the cooling of a solution, the solute may be deposited in a metastable form. If such forms are present, it is better to convert them to the stable form by thermal treatment (Gatlin and DeLuca, 1980; Rey, 1964), a process which involves alternately warming and cooling the sample.

(4) The degree of supercooling of the water in the sample is the difference between the equilibrium freezing temperature of the water in the sample $\left(0^{\circ} \mathrm{C}\right)$ and the actual temperature at which ice crystals begin to form as the sample is cooled. For example, if the actual temperature at which ice first begins to form is $-5^{\circ} \mathrm{C}$, the degree of supercooling is $5^{\circ} \mathrm{C}$. In freeze-drying, some degree of supercooling is generally desirable because it causes a rapid growth of ice crystals and therefore may help to prevent the formation of a glaze on the surface of the product (Jennings, 1980a).

Gatlin and DeLuca (1980) have studied the thermal characteristics of solutions of some antibiotics include cefazolin sodium, a cephalosporin, by DSC. They found that the DSC warming thermogram of cefazolin sodium showed an exotherm which was interpreted as representing the crystallization of the compound during warming. In other words, during cooling, the solute was deposited in a metastable amorphous state which underwent a transition to the stable crystalline state during warming. Subsequent freeze-drying of a cefazolin sodium sample, which had been induced to crystallize by thermal treatment, yielded a crystalline end-product.

The objectives of this work were to: (a) examine the thermal characteristics of solutions of several cephalosporins by means of DSC; (b) determine whether such cephalosporins form eutectic mixtures with water; and (c) evaluate the usefulness of DSC in studying freezing characteristics (such as those outlined in (1)-(4) above) of the solutions. Cephalosporins were selected for this study because, although some are marketed as freeze-dried products, they are usually difficult to lyophilize satisfactorily. The reason for this difficulty may lie in their freezing characteristics.

\section{Materials and Methods}

\section{Materials}

Cefamandole Nafate for Injection (Mandol, Eli Lilly and $\mathrm{Co}$ ), Sterile Cefonicid Sodium (Monocid, Smith Kline \& French Laboratories), Sterile Cefotaxime Sodium (Claforan, Hoechst-Roussel Pharmaceuticals), Cephalothin Sodium for Injec- 
tion (Keflin, Eli Lilly and Co), Sterile Cephapirin Sodium (Cefadyl, Bristol Laboratories) and Moxalactam Disodium for Injection (Moxam, Eli Lilly and $\mathrm{Co}$ ) were used in the study and are available commercially. The Differential Scanning Calormeter used was a Perkin Elmer $2 \mathrm{C}$ model. It was calibrated and checked with $n$-octane [melting point $216.4 \mathrm{~K}\left(-56.8^{\circ} \mathrm{C}\right)$ ], $n$-decane [melting point $243.5 \mathrm{~K}\left(-29.7^{\circ} \mathrm{C}\right)$ ] and water [melting point $\left.273.2 \mathrm{~K}\left(0.0^{\circ} \mathrm{C}\right)\right]$

\section{Method}

Solutions of the cephalosporins, varying from $1 \% \mathrm{w} / \mathrm{v}$ to $20 \% \mathrm{w} / \mathrm{v}$, were made in double-distilled water. Each sample solution was weighed into a specially designed aluminum pan which was then sealed with a cap. The sample size varied from 8 to $15 \mathrm{mg}$. The sample pan and an empty reference pan were loaded onto the DSC at room temperature and frozen by means of liquid nitrogen at a programmed rate of $2.50^{\circ} \mathrm{C} / \mathrm{min}$ to 193.0 $\mathrm{K}\left(-80.2^{\circ} \mathrm{C}\right)$. The sample and reference were held at this temperature for about $10 \mathrm{~min}$ and then warmed at $1.25^{\circ} \mathrm{C} / \mathrm{min}$ to $283.0 \mathrm{~K}\left(9.8^{\circ} \mathrm{C}\right)$.

\section{Basic principles of $D S C$}

The principles of DSC have been discussed in detail elsewhere (Watson et al., 1964). Briefly, the aim is to keep the temperatures of the sample and reference equal as both are warmed and cooled at a programmed rate. When the sample undergoes a phase transition (e.g. freezing, melting), it either liberates heat (during freezing) or absorbs heat (during melting). In the former case, which is an exothermic process, the liberated heat is conducted away from the sample. In the latter case (an endothermic process), heat flows toward, and is absorbed by, the sample. In either case, the direction of heat flow is always such that it tends to equalize the temperatures of the sample and the reference. The heat flow to, or away from, the sample is compared electronically to that of the reference and the result is displayed as a peak. A downward peak, by convention, indicates an exothermic transition while an upward peak represents an endothermic transition.

\section{Results and Discussion}

\section{Eutectic mixtures}

Compounds which form eutectic mixtures with water show characteristic DSC thermograms. Such a compound is best illustrated by sodium chloride. If an aqueous solution of this salt, at a concentration below the eutectic composition of $23.3 \% \mathrm{w} / \mathrm{w}$ sodium chloride (Rodebush, 1918), is frozen to about $-40^{\circ} \mathrm{C}$ and then warmed, the DSC thermogram obtained is shown schematically in Fig. 1. The thermogram may be explained briefly as follows. The first peak (A) represents the melting of the eutectic mixture consisting of finely divided crystals of ice and sodium chloride. The temperature at which this occurs is called the eutectic temperature $\left(T_{\text {eu }}\right)$ and it is $-21.12^{\circ} \mathrm{C}$ for sodium chloride (Rodebush, 1918). Below $T_{\text {eu }}$, the sample is completely solidified with no liquid phase and consists only of coarse crystals of ice (which were first deposited during cooling) and very small, intimately mixed crystals of ice and sodium chloride (which were deposited below $T_{\mathrm{eu}}$ during cooling). During the melting of the eutectic mixture, the temperature of the frozen sample must remain constant as required by Gibbs Phase Rule (Findlay and Campbell, 1938; Pope and Judd, 1977) until one phase, the solid sodium chloride, disappears. Only then does the temperature begin to increase

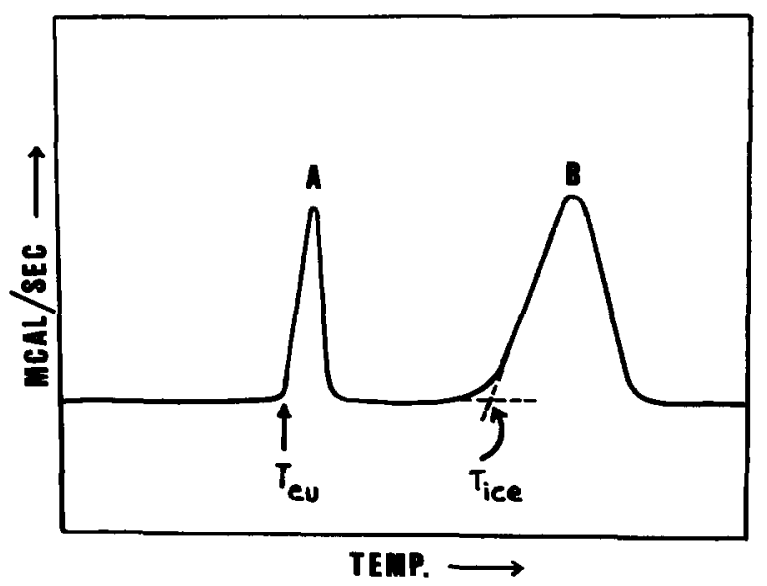

Fig. 1. Schematic DSC warming thermogram of the frozen aqueous solution of a compound which forms a eutectic with water (see text for explanation). $T_{\text {eu }}=$ eutectic temperature; $T_{\text {ice }}=$ melting temperature of the ice in the sample. 


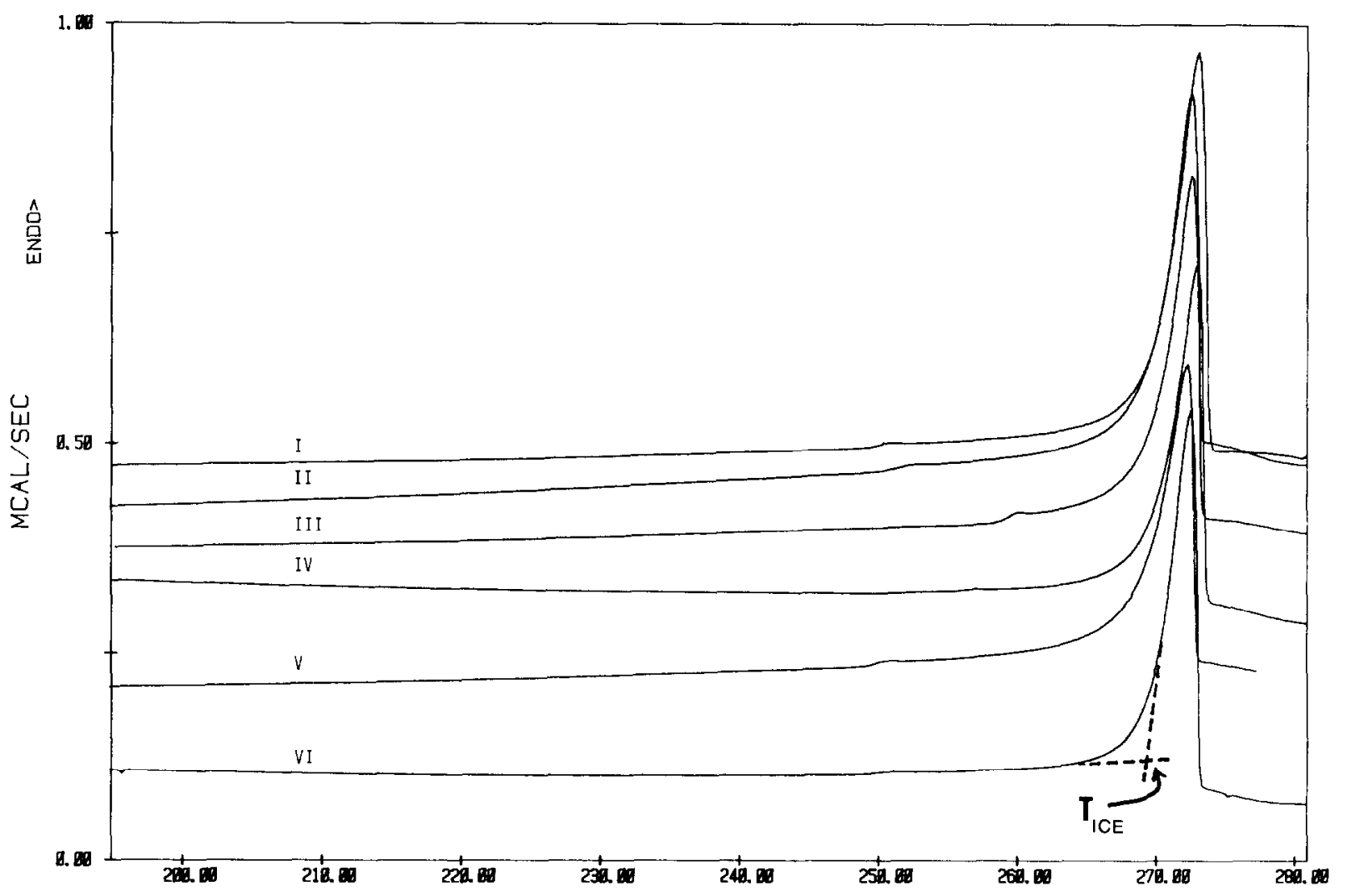

TEMPERATURE (K)

Fig. 2. Normalized DSC warming thermograms of $20 \% \mathrm{w} / \mathrm{v}$ solutions of cephalosporins. I = Sterile Cephapirin Sodium; II $=$ Sterile Cefonicid Sodium; III = Sterile Cefotaxime Sodium; IV = Cefamandole Nafate for Injection; V = Moxalactam Disodium for Injection; VI = Cephalothin Sodium for Injection.

again, hence the sharp peak. After the melting of the eutectic mixture, the sample now contains sodium chloride solutions and ice, and the temper- ature increases again until another peak (B), representing the melting of the ice, is seen. At a concentration above the eutectic composition, only

\section{TABLE 1}

Significant thermal events in the warming thermograms of frozen cephalosporin solutions $(20 \% \mathrm{w} / \mathrm{v})$

\begin{tabular}{|c|c|c|c|c|}
\hline \multirow[t]{2}{*}{ Cephalosporin } & \multicolumn{2}{|c|}{$\begin{array}{l}\text { Onset of first endothermic shift } \\
\text { ("glass transition") temperature }\end{array}$} & \multicolumn{2}{|c|}{ Melting temperature of the ice in the sample $\left(T_{\text {ice }}\right)$} \\
\hline & $\mathrm{K}$ & ${ }^{\circ} \mathrm{C}$ & $\bar{K}$ & ${ }^{\circ} \mathrm{C}$ \\
\hline Cefonicid Sodium (II) & 250.7 & -22.5 & 268.8 & -4.4 \\
\hline Cefotaxime Sodium (III) & 258.3 & -14.9 & 269.0 & -4.2 \\
\hline Cefamandole Nafate (IV) & 256.5 & -16.7 & 269.5 & -3.7 \\
\hline
\end{tabular}


one peak, representing the melting of the eutectic, is scen and this peak occurs at $T_{\mathrm{eu}}$. Since all the ice in the sample is associated with eutectic mixture, once the latter melts, no more ice remains in the sample. Instead, we have only the solution of sodium chloride (with a concentration equal to the eutectic composition) and some solid sodium chloride which dissolves as the sample is warmed. Since no separate ice phase is present in the sample, no endotherm corresponding to the melting of the ice is seen and the dissolution of the remaining solid sodium chloride does not alter the baseline significantly as the sample is warmed.

In Figs. 2-4, all thermograms are plotted per milligram of sample (i.e. normalized) to correct for the varying amounts of sample solution used.
Fig. 2 shows the normalized warming thermograms obtained for $20 \% \mathrm{w} / \mathrm{v}$ solutions of the cephalosporins. There is no thermal event below $248 \mathrm{~K}\left(-25.2^{\circ} \mathrm{C}\right)$. Above this temperature, however, all the compounds studied showed an endothermic shift somewhat similar to the glass transition occurring in polymers. The "glass transition" temperatures are shown in Table 1. Following the "glass transition" is the prominent endothermic peak indicating the melting of the ice in the frozen sample. The temperature at which this occurs, $T_{\text {ice }}$, is shown for each sample in Table $1 . T_{\text {ice }}$ was determined as illustrated for Cephalothin Sodium for Injection (VI) in Fig. 2.

Fig. 3 shows normalized warming thermograms for $1 \% \mathrm{w} / \mathrm{v}$ Sterile Cephapirin Sodium and Sterile

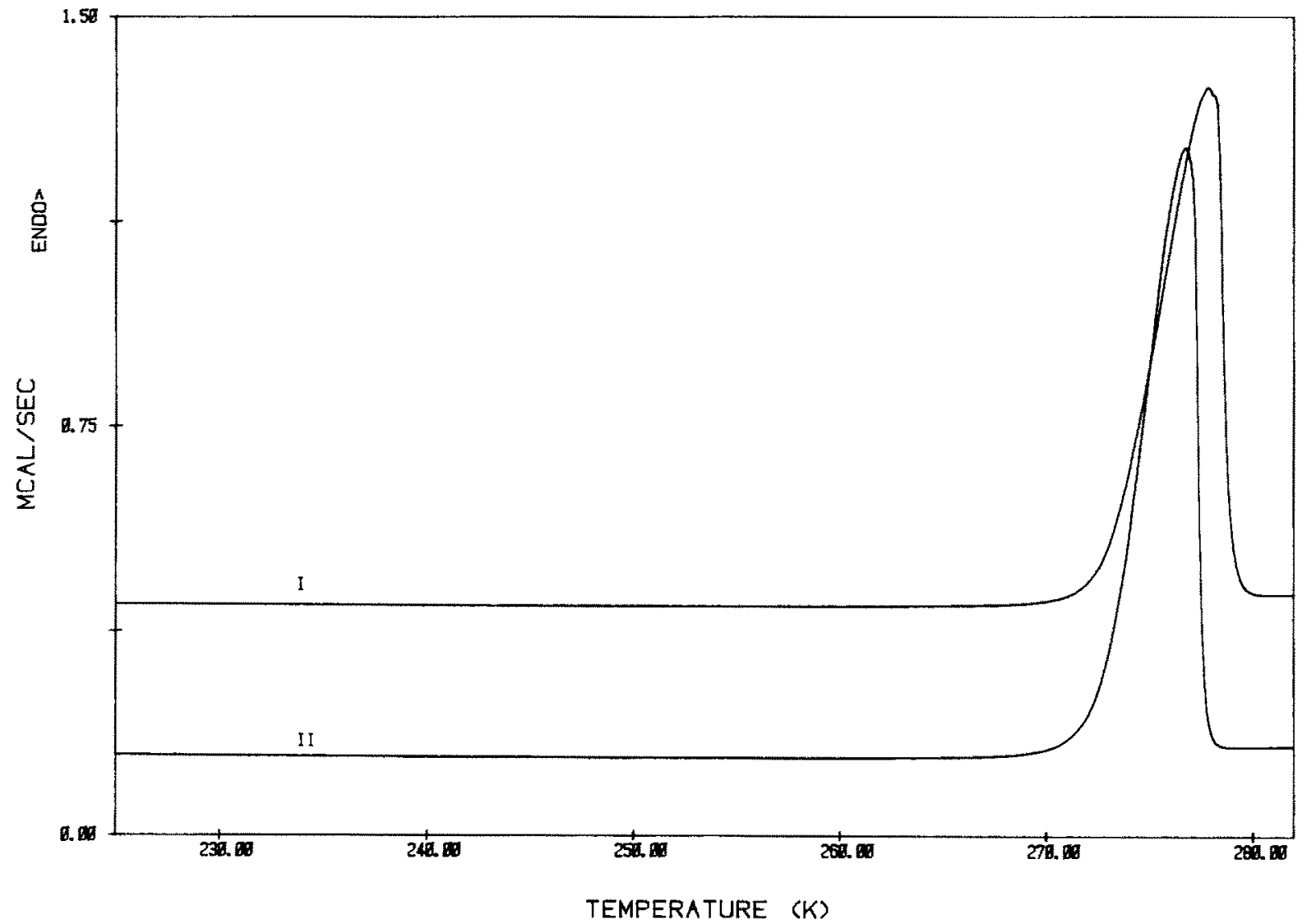

Fig. 3. Normalized DSC warming thermograms of $1 \% \mathrm{w} / \mathrm{v}$ solutions of Sterile Cephapirin Sodium (I) and Sterile Cefonicid Sodium 
Cefonicid Sodium. Only the endotherm indicating the melting of the ice is seen; there is no evidence of a "glass transition". Cephalosporin solutions as low as $1 \% \mathrm{w} / \mathrm{v}$ showed only one peak, suggesting that they do not form eutectics with water.

DSC scans of solutions ranging from $20 \% \mathrm{w} / \mathrm{v}$ to as low as $1 \% \mathrm{w} / \mathrm{v}$ were run to ensure that the absence of a eutectic peak was not caused by the use of solutions higher in concentration than the eutectic composition.

The evidence therefore suggests that the cephalosporins in this study do not crystallize during cooling.

\section{The "glass transition"}

In Fig. 2, for all 6 cephalosporins shown, a slight endothermic event occurs at temperatures shown in Table 1. As mentioned earlier, these shifts, some of which are more pronounced than others and are first observed at concentrations of about $5 \% \mathrm{w} / \mathrm{v}$, are similar to the type seen in DSC thermograms of polymers when they undergo a glass transition during heating. Such polymers are hard and glassy below the glass transition temperature but become more flexible at and above it. Since it involves a change in heat capacity, the glass transition in a DSC thermogram is indicated by a change in the slope of the baseline. With regard to the cephalosporins under consideration, we think the "glass transition" represents a softening of the interstitial fluid hardened during freezing. The interstitial fluid (or more generally, interstitial material) is the region interspersed between the ice layers. It contains the solute. In more dilute solutions, the "glass transition" is less perceptible and, as shown in Fig. 3, it is not observable in very dilute solutions. This is interpreted as being due to the negligible amount of "glassy" material formed in the very dilute solutions. After the "glass transition", as the warming progresses, the unmelted ice finally melts giving rise to the endothermic peak in Fig. 2. As the ice melts, the solute particles deposited during freezing go back into solution.

\section{Metastable states of the solute}

Since no exotherm is observed in the DSC warming thermograms, it appears that none of the compounds under study goes into a metastable state during cooling. As mentioned earlier, the appearance of an exotherm on warming, suggests the formation of a metastable, amorphous state (during the previous cooling cycle), which is transformed into a stable, crystalline state during warming.

\section{Degree of supercooling}

Fig. 4 shows the cooling thermograms obtained for $20 \% \mathrm{w} / \mathrm{v}$ solutions of the cephalosporins. The onset of freezing, denoted by the sharp exotherm, ranges from $254.8 \mathrm{~K}\left(-18.4^{\circ} \mathrm{C}\right.$ to $249.3 \mathrm{~K}$ $\left(-23.9^{\circ} \mathrm{C}\right)$. The exotherm in each case represents the crystallization of the water in the sample. This is followed by a small exothermic shift occurring at about $7^{\circ} \mathrm{C}$ below the onset of freezing. Between $240 \mathrm{~K}\left(-33.2^{\circ} \mathrm{C}\right)$ and $193 \mathrm{~K}\left(-80.2^{\circ} \mathrm{C}\right)$, no other thermal event is evident. Since the equilibrium freezing temperature of water is $0^{\circ} \mathrm{C}$, the degree of supercooling may be calculated from Fig. 4 (the difference between the exothermic peak temperature and $273.2 \mathrm{~K}$ ) as ranging from 18 to $24\left({ }^{\circ} \mathrm{C}\right.$ or $\left.\mathrm{K}\right)$. This high degree of supercooling in the aluminum pan of the Differential Scanning Calorimeter implies an extremely fast ice growth throughout the sample. When solutions of the same cephalosporins were cooled in glass vials, the degree of suprecooling was between 4 and $8\left({ }^{\circ} \mathrm{C}\right.$ or $\mathrm{K}$ ), implying a much slower ice growth. This difference between glass and aluminum containers suggests that DSC results should be extrapolated to real freeze-drying conditions with some caution.

Determination of $T_{c . s}$ and $T_{i m}$ for cephalosporin solutions

In the determination of $T_{\mathrm{cs}}$ and $T_{i \mathrm{~m}}$ of frozen cephalosporin solutions for the purpose of freezedrying, the DSC results do not give precise information because the compounds do not form eutectic mixtures with water. As mentioned earlier, the change in the electrical resistance of a frozen matrix has been used to measure eutectic temperatures during warming (Rey, 1960; Deluca and Lachman, 1965a and b). Typically, when the interstitial eutectic material melts, there is a sharp decrease in resistance which indicates $T_{\text {eu }}$. However, for compounds which do not form eutectics, 


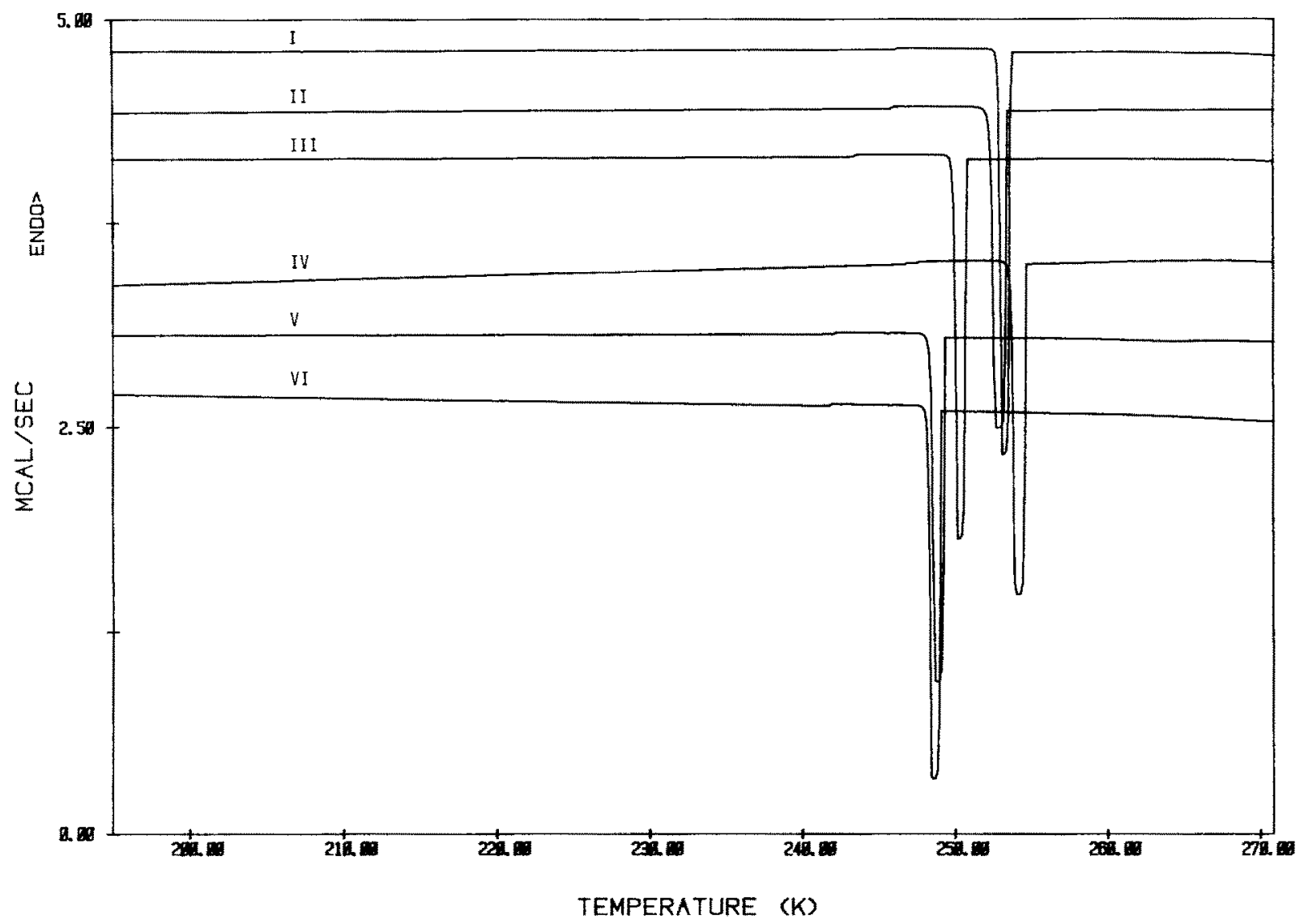

Fig. 4. Normalized DSC cooling thermograms of $20 \% \mathrm{w} / \mathrm{v}$ solutions of cephalosporins (symbols are the same as in Fig. 2).

the change in resistance is not as sharp and is therefore more difficult to interpret (Rey, 1960). Resistance measurcments obtained for these cephalosporins in our laboratory (unpublished) have neither indicated a clear $T_{\mathrm{im}}$ nor shed more light into the nature of the interstitial material near the "glass transition".

In conclusion, DSC studies of cephalosphorin solutions show that they typically do not crystallize during freezing and do not form eutectics. The ones examined also do not go into metastable states during freezing. In addition, the physical state of the "frozen" matrix (in terms of presence or absence of a liquid phase) cannot be clearly ascertained by DSC because the compounds do not form eutectics with water. Therefore, in the determination of parameters to be employed in the design of an optimum lyophilization cycle for compounds like these, DSC may be of limited use.

\section{References}

DeLuca, P. and Lachman, L., Lyophilization of pharmaceuticals. I: Effect of certain physical-chemical characteristics, J. Pharm. Sci., 54 (1965) 617-624.

DeLuca, P. and Lachman, L., Lyophilization of pharmaceuticals. IV: Determination of eutectic temperatures of inorganic salts, J. Pharm. Sci., 54 (1965) 1411-1415.

DeLuca, P.P., Freeze-drying of pharmaceuticals, J. Vac. Sci. Technol., 14 (1977) 620-629.

Findlay, A. and Campbell, A.N., The Phase Rule and Its Applications, Dover Publications, New York, NY, 1938.

Flosdorf, E.W., Freeze-Drying, Reinhold, New York, NY, 1949. 
Gatlin, L. and DeLuca, P.P., A study of phase transitions in frozen antibiotics solutions by differential scanning calorimetry, J. Parent. Drug Assoc., 34 (1980) 398-403.

Harris, R.I.C. (Ed.), Biological Applications of Freezing and Drying, Academic Press, New York, NY, 1954.

Jennings, T.A., Optimization of the lyophilization schedule, Drug Cosmet. Ind., Nov. (1980) 43-52, 118.

Jennings, T.A., The effect of resistivity probe design on the measurement of the freezing temperature of lyophilized formulations, J. Parent. Drug Assoc, 34 (1980) 109-126.

Patel, R.M. and Hurwitz, A., Eutectic temperature determination of preformulation systems and evaluation by controlled freeze-drying, J. Pharm. Sci., 61 (1972) 1806-1810.

Pope, M.I. and Judd. M.D., Differential Thermal Analysis, Heyden, Belmawr, N.J., 1977, Chap. 6.
Rey, L.R., Thermal analysis of eutectics in freezing solutions, Ann. N.Y. Acad. Sci., 85 (1960) 510-534.

Rey, L., Fundamental aspects of lyophilization. In Rey, L. (Ed.), Theoretical and Industrial Aspects of lyophilization, Hermann, Paris, 1964, pp. 22-43.

Rodebush, W.H., The freezing points of concentrated salt solutions and the free energy of solution of salts, J. Am. Chem. Soc., 40 (1918) 1204-1213.

Watson, E.S., O'Neill, M.J., Justin, J. and Brenner, N., A differential scanning calorimeter for quantitative differential thermal analysis, Anal. Chem, 36 (1964) 1233-1238.

Williams, N.A. and Polli, G.P., The lyophilization of pharmaceuticals: A literature review, J. Parent. Sci. Technol., 38 (1984) 48-59. 